\section{Medicine in Germany}

SIR-Your country profile of German medical care and research ( $\mathrm{Dec} 14$, p 1631), ${ }^{1}$ notwithstanding some of the criticisms made, may have painted too rosy a picture. Lorenz chooses the euphemism of "different" to describe the quality of $\mathrm{G}$ erman clinical research, and notes that only two of 32 German fifth-year medical students could correctly identify The L ancet, citing this as justification for the publication of research in the German language. Rather than being support for German language publication, it seems an indication of how poor at least some aspects of $\mathrm{G}$ erman medical training are (given that The Lancet has the second highest scholarly impact of any medical journal $\left.{ }^{2,3}\right)$. Perhaps German students and physicians would be best served by gaining access to the best contemporary medical literature, which is published in English, the lingua franca of modern science.

Lorenz notes that German clinical researchers have the impression that their work will not be accepted by the well-known journals, and therefore submit to specialist journals. He claims that in a $M$ arburg research group's case, journals were chosen on the basis of having impact factors (IF) of greater than 1 , and "the presence of individuals on the editorial board who can testify to the authors' credibility". IF, which would be an objective criterion for journal quality, ${ }^{2,3}$ is not fulfilled in the German language journals listed by L orenz, which have IF of less than $0 \cdot 7 .{ }^{3}$ If they had had IF greater than 1 at the time of the Marburg group's publication, the subsequent shrinkage speaks to their declining impact.

Rothmund aptly notes the destructive influence of contemporary so-called $G$ reen politics on medical advances. What is not noted in the country profile is the lingering effect of the 1932-33 German elections, which led to the removal of the best scientists in Germany, their replacement with loyal party members (who set the tone for succeeding generations), and an exacerbation of the rigid autocratic approach. ${ }^{4}$ Authoritarian and political goals continue to triumph over quality, and new ideas, by dint of their divergence being intrinsically suspect, are often crushed, precluding scientific advances. ${ }^{4}$

The 50th anniversary of the doctors' trial at Nuremberg should remind us that $\mathrm{G}$ erman medicine has a murderous past (most German physicians were $\mathrm{N}$ azi party members), so the reported reluctance of many Germans to be research subjects should not be surprising. It is noteworthy that the crimes which masqueraded as investigations were not only extraordinarily vicious-they were also often so poorly designed as to yield useless data. ${ }^{5}$

\section{Stuart Brody}

Department of Medical Psychology, University of Tübingen, D-72074 Tübingen, Germany

1 Selbmann HK, Flöhl R, Volk H-D, et al. Country profile: G ermany. L ancet 1996 . 348: 1631-39.

2 Brody S. I mpact factor as the best operational measure of medical journals. Lancet 1995; 346: 1300-01.

31995 Science Citation Index Journal Citation Reports. Philadel phia: ISI, 1996.

4 Brody S. G erman education. Science 1996; 273: 1029-30.

5 Berger RL. N azi Science-T he D achau hypothermia experiments. N Engl J M ed 1990; 322: 1435-40.

SIR-Clinical research in Germany is obviously in a desolate state, ${ }^{1}$ and distinguished German scientists continue to work abroad. H owever, the dilemma begins when medical trainees are first faced with whether to pursue a career in academic medicine. By contrast with many other western countries there are no career structures or training schemes for academic medicine, and careers in clinical and academic medicine often run along side each other for years, without distinction. Good scientific practice such as basic research techniques, statistics, epidemiology, and presentation skills are rarely taught and often not required for $M D$ or $P h D$ programmes. Requirements for senior lecturer posts (Privat Dozent) vary among federal states and even among universities, and are sometimes poor by comparison with international standards. Of course not all is golden in the Anglo-American systems, which have similar financial constraints, but a more clear-cut separation between clinical and academic medicine and the development of career structures give these countries a clear advantage.

$\mathrm{N}$ ot all is lost for the scientific tradition of Germany. The recent introduction of interdisciplinary research units by the DFG (D eutsche Forschungsgemeinschaft) is the right way forward to provide a thriving environment in which clinical research can once more prosper.

\section{O A F Bodamer}

Nutrition, Metabolism, Endocrinology, and Dermatology Unit, Institute of Child Health, London WCIN IEH, UK

1 Selbmann HK, Flöhl R, Volk H-D, et al. Country profile: G ermany. L ancet 1996; 348: 1631-39.

SIR-In their review of the German health care system, Selbmann and colleagues $^{1}$ lament the fact that Germany is no longer in the lead in medical research. Various reasons are offered, yet the most important is not mentioned: the enormous brain drain that happened during the Third Reich. Thousands of Jewish doctors either left the country or perished in concentration camps in this era. ${ }^{2}$ The medical elite of that time was dominated by Jews. In some medical schools, about $80 \%$ of the staff had to go. ${ }^{3} \mathrm{~A}$ loss of this magnitude cannot be sustained without severe and long-term effects on the quality of research.

\section{E Ernst}

Department of Complementary Medicine, Postgraduate Medical School, Exeter EX2 4NT, UK

1 Selbmann HK, Flöhl R, Volk H-D, et al Country profile: G ermany. Lancet 1996; 348: 1631-39.

2 K uter M H. D octors under $\mathrm{H}$ itler. Chapel $\mathrm{H}$ ill, N C: U niversity of N orth Carolina Press, 1989.

3 Ernst $\mathrm{E}$. A leading medical school seriously damaged: Vienna 1938. A nn Intern M ed 1995; 122: 789-92.

\section{Declining cancer mortality in European Union}

SIR-A fter steady rises registered since early this century, and a peak rate in 1990, age-standardised cancer mortality rates in the U SA declined by $3 \cdot 1 \%$ in both sexes combined, between 1990 and 1995. About half the decline was attributed to levelling of the lung and other tobacco-related cancer epidemic, and the remaining proportion to several factors, including reduced exposure to occupational carcinogens, prevention and early diagnosis, and improved treatment. ${ }^{1,2}$

$M$ onitoring of a corresponding trend for Europe is also important. ${ }^{3}$ We updated analyses for the European U nion on the basis of death certificates issued and population estimates for the 15 countries of the Union obtained from the WHO database. ${ }^{4}$ Agestandardised and sex-standardised mortality rates for all neoplasms, lung, and stomach cancers are shown in the table, together with mortality from all causes and the proportion of cancer deaths. M ortality from all causes declined steadily by $38 \%$ between 1960 and 1992. T otal cancer mortality rates in both sexes combined have increased by $44 \%$ since 1960 , to reach a peak in 1988. Thereafter, they declined by $2.8 \%$ in 1992 . Likewise, lung cancer rates in both sexes combined increased by $58.5 \%$ between 1960 and 1988 , and declined by $3.9 \%$ in 1992 . Thus, almost a third of the decline was accounted for by lung cancer alone, and probably about a half by the complex of tobacco-related neoplasms. ${ }^{5}$ By comparison with the USA, the evolution of the tobacco-related lung 


\begin{tabular}{|c|c|c|c|c|c|c|}
\hline & All causes & All cancers & Lung cancer & Stomach cancer & Other cancers & $\mathrm{CPM}^{*} \%$ \\
\hline \multicolumn{7}{|l|}{ Year } \\
\hline 1960 & $824 \cdot 2$ & 140.5 & 19.5 & 24.9 & $96 \cdot 1$ & $17 \cdot 7$ \\
\hline 1970 & $737 \cdot 5$ & $145 \cdot 0$ & $25 \cdot 2$ & $19 \cdot 3$ & $100 \cdot 5$ & $19 \cdot 5$ \\
\hline 1980 & $635 \cdot 2$ & $146 \cdot 1$ & $29 \cdot 7$ & $13 \cdot 7$ & $102 \cdot 7$ & 21.9 \\
\hline 1985 & $581 \cdot 5$ & $146 \cdot 0$ & $30 \cdot 4$ & $11 \cdot 6$ & $104 \cdot 0$ & $23 \cdot 1$ \\
\hline 1988 & 541.9 & $146 \cdot 7$ & 30.9 & $10 \cdot 6$ & $105 \cdot 2$ & $24 \cdot 7$ \\
\hline 1989 & 533.5 & $145 \cdot 5$ & $30 \cdot 5$ & $10 \cdot 1$ & $104 \cdot 9$ & $24 \cdot 8$ \\
\hline 1990 & $526 \cdot 2$ & 143.9 & $30 \cdot 2$ & 9.9 & $103 \cdot 8$ & $24 \cdot 7$ \\
\hline 1991 & $519 \cdot 3$ & 143.8 & $30 \cdot 2$ & $9 \cdot 6$ & $104 \cdot 0$ & 24.9 \\
\hline 1992 & $507 \cdot 6$ & $142 \cdot 6$ & $29 \cdot 7$ & $8 \cdot 7$ & $104 \cdot 2$ & $25 \cdot 2$ \\
\hline $1993 \dagger$ & $539 \cdot 1$ & 140.6 & $27 \cdot 6$ & $10 \cdot 0$ & $103 \cdot 0$ & 23.8 \\
\hline $\begin{array}{l}\text { Change in rate, } \\
1988-92\end{array}$ & $\begin{array}{l}-34 \cdot 3 \\
(-6 \cdot 3 \%)\end{array}$ & $\begin{array}{l}-4 \cdot 1 \\
(-2 \cdot 8 \%)\end{array}$ & $\begin{array}{l}-1 \cdot 2 \\
(-3.9 \%)\end{array}$ & $\begin{array}{l}-1.9 \\
(-17 \cdot 9 \%)\end{array}$ & $\begin{array}{l}-1.0 \\
(-1.0 \%)\end{array}$ & \\
\hline
\end{tabular}

*CPM , cancer proportional mortality. †Data only for Austria, Denmark, Finland, Germany, Greece, Luxembourg, Netherlands, and Portugal.

Table: Age-standardised and sex-standardised mortality rates per 100000 (world standard population) from selected causes in European Union, 1960-92

cancer epidemic is still in its early phase in European women. ${ }^{5}$ About half of the decline in total cancer mortality not attributable to tobacco includes a continuing fall in deaths from gastric cancer.

Although data for 1993 were only available for eight countries, the downward trend since 1988 for cancer mortality was confirmed.

Supported by Swiss L eague Against C ancer, Italian Association for $C$ ancer Research, and the C N R-A pplicazioni Clinich della Ricerca Oncologi Applied Project.

*Fabio Levi, Carlo La Vecchia, Eva Negri, Franca Lucchini

* Institut Universitaire de Médecine Sociale et Préventive, 1005 Lausanne, Switzerland; Istituto di Statistica Medica e Biometria, Università degli Studi di Milano, Italy; and Istituto di Ricerche Farmacologiche "Mario Negri", Milano

1 M acready N. O verall U S cancer-mortality rate declines. L ancet 1996; 348: 1435.

2 Cole P, Rodu B. D eclining cancer mortality in the U nited States. Cancer 1996; 78: 2045-48.

3 L evi F, La Vecchia C, Lucchini F, N egri E. Cancer mortality in Europe, 1990-92. Eur J Cancer Prev 1995; 4: 389-417.

4 N egri E, La Vecchia C, F ranceschi S, L evi F. Patterns of mortality from major cancers in Europe. C ancer E pidemiology, B iomarkers \& Prevention 1994; 3: 531-36.

5 La Vecchia C, Boyle $P$, Franceschi S, et al. Smoking and cancer with emphasis on Europe. Eur J Cancer 1991; 27: 94-104.

\section{Balloon ripening of the cervix}

SIR-M any young physicians believe that nearly everything we know in obstetrics and gynaecology was discovered in recent decades. H owever, some of the so-called recent breakthroughs were described long ago. For example, Richard Lower (1631-91) was the first person to show interest in blood transfusion; the first transfusion was done by him in 1665 , with sheep's blood. The first abdominal operation for ectopic pregnancy was performed in 1759 by John Bard
(1716-99), and salpingectomy for ectopic pregnancy was achieved by Lawsen Robert Tait (1845-99) in 1884. Epidural analgesia for labour pain was introduced by $W$ alter Stoeckel (1871-1961) in 1909; he achieved immediate and total anaesthesia of the lower body in six parturients by subarachnoid injection of cocaine.

It is generally accepted ${ }^{1}$ that use of inflated balloons to induce cervical ripening and labour was first described by Embrey and M ollison in 1967, ${ }^{2}$ and modified by Atad and colleagues in 1991. ${ }^{3}$ However, the use of these balloons was first described by Barnes in April, 1861, in Obstetrical T ransacricus volume III. ${ }^{4} \mathrm{~B}$ arnes used a rubber balloon, filled with water; the induction-to-delivery interval was 3-4 $h,{ }^{5}$ which is impressive compared with 6-24 $\mathrm{h}$ reported in a recent review. ${ }^{1}$ Corner ${ }^{5}$ noted: "I may briefly mention what struck me particularly in the use of these instruments: the ease with which they were introduced within the os .... : the absence of complaint on the part of the patient; and their speedy action in dilating the parts and inducing natural expulsive pains".

E ven more fascinating is comparison of the hypothesis of Barnes's time with that of today on how the balloon exerts its effect. At the beginning of the century, the mechanism of induction of labour was thought not to be purely by mechanical dilation of cervix: a foreign-body effect on the cervix was also considered to stimulate uterine contraction. Modern belief holds that the basic mechanism of cervical ripening by balloon seems to be direct pressure and overstretching of the lower uterine segment and cervix, ${ }^{1}$ and that overstretching results in increased prostaglandin concentrations in the amniotic fluid and maternal plasma; on release, the prostaglandins are involved in cervical softening and subsequent uterine contractions.

After more than 100 years the story of ripening the unfavourable cervix with a balloon mechanism seems to have found a beginning, middle, and end. H owever, perhaps, the description of yet another substance may in the future elucidate more accurately the biochemical mechanism involved in cervical ripening .

* Samuel Lurie, David Rabinerson

* Department of Obstetrics and Gynaecology, Kaplan Hospital, 76100 Rehovot, Israel, and Department of Obstetrics and Gynaecology, Bellinson Hospital, Petah Tikva.

1 Sherman DJ, Frenkel E, T ovbin J, A rieli S, Caspi E, Bukovsky I. Ripening of the unfavourable cervix with extra-amniotic catheter balloon: clinical experience and review. O bstet G ynecol Surv 1996; 51: 621-27.

2 Embrey M P, M ollison BG. The unfavorable cervix and induction of labor using a cervical balloon. J O bstet G ynaecol B r Commonw 1967; 74: 44-48.

3 Atad J, Bornstein J, Petrikovsky B, Calderon I, Sorokin Y, A bramovici H . $\mathrm{N}$ onpharmaceutical ripening of the unfavourable cervix and induction of labor by a novel double balloon device. 0 bstet Gynecol 1991; 77: 146-52.

4 Woodman WB. Induction of labor at the eighth month, and delivery of a living child in less than four hours by Dr Barnes's method. Lancet 1863; i: 10-11.

5 Corner FM. On a case of induction of premature labour by D $\mathrm{r}$ Barnes's method. L ancet 1863; i: 115-16.

\section{Use of unlicensed nitric oxide in Austria}

SIR-The alert given by $W$ arren and $\mathrm{H}$ iggenbottam ${ }^{1}$ on the benefits and risks of nitric oxide ( $\mathrm{NO}$ ) inhalation is a reminder of the possible adverse consequences of the use of an unlicensed medicine. Generally, the distribution of $\mathrm{NO}$ for medical purposes accords with the ethical rules for experimentation with drugs, but less restrictive controls seem to exist when the medical authorities allow compassionate use of $\mathrm{NO}$ in lifethreatening conditions, without permission of an ethical committee or documentation. Joannidis and colleagues ( $\mathrm{N}$ ov 23, p 1448) ${ }^{2}$ report one lethal complication, and another with a serious outcome, which caution against use of inhaled NO in intensive care under certain conditions. The European $M$ edical Product Agency guidelines ${ }^{3}$ and guidelines from a sponsor of $\mathrm{NO}$ clinical trials ${ }^{4}$ mention bleeding disorders as possible side-effects of NO therapy. H owever, these guidelines may not be known to all compassionate users.

We were surprised to learn that $\mathrm{NO}$ containing cylinders could be directly purchased from the Austrian subsidiary of a transnational company as a "technical-gas specialty", which ignores the experimental drug status of $\mathrm{NO}$ and 